\title{
Comprehensive knowledge on cervical cancer, attitude towards its screening and associated factors among women aged 30-49 years in Finote Selam town, northwest Ethiopia
}

\author{
Alehegn Bishaw Geremew ${ }^{1 *}$, Abebaw Addis Gelagay ${ }^{1}$ and Telake Azale ${ }^{2}$
}

\begin{abstract}
Background: Screening services for cervical pre-cancerous lesions is currently available for all women aged 30-49 years at public hospitals in Ethiopia. Though women's knowledge and their attitude are determinants for the uptake the screening service, there is limited information on these regards. Therefore, this study aimed to assess comprehensive knowledge on cervical cancer, attitudes towards the screening, and associated factors among women aged 30-49 years at Finote Selam town, northwest Ethiopia.

Methods: A community based cross-sectional study was conducted from March 30, to April 15, 2017. The sample size calculated for this study was 1224 and a cluster sampling technique was used to select the participants from three randomly selected kebeles. Epi-Info version 7 and Statistical Package for Social Sciences version 20 were used for data entry and analysis respectively. A binary logistic regression model was used. In multivariable logistic analysis, adjusted odds ratio with a 95\% confidence interval was used to determine the presence and strength of associations between covariate and outcome variable.
\end{abstract}

Results: A total of 1137 women participated in this study. Nearly one third, 30.3\% (95\%Cl: 27.7, 32.9) of the women had knowledge of cervical cancer, and 58.1\% (95\% Cl: 55, 62.2) had a favorable attitude towards cervical cancer screening. In the multivariable analysis, having college and above education ( $\mathrm{AOR}=7.21,95 \% \mathrm{Cl}: 3.41,15.29)$, knowing someone with cervical cancer (AOR $=5.38,95 \% \mathrm{Cl}: 2.38,12.15)$, and having a history of sexually transmitted diseases $(\mathrm{AOR}=2.75$, $95 \% \mathrm{Cl}: 1.24,6.04)$ were significantly associated with knowledge on cervical cancer. Meanwhile, college and above educational status ( $\mathrm{AOR}=2.56,95 \% \mathrm{Cl}: 1.14,5.69)$, knowing someone with cervical cancer ( $\mathrm{AOR}=3.24,95 \% \mathrm{Cl}: 1.14,9.15$ ), and having knowledge of cervical cancer (AOR $=3,95 \% \mathrm{Cl}: 1.97,4.29)$ were positively associated with favorable attitudes towards cervical cancer screening.

Conclusion: The proportion of women who had knowledge on cervical cancer was low where as relatively, a large proportion of the study participants in this study had favorable attitude towards cervical cancer screening. Educational status, knowing someone with cervical cancer, a history of sexually transmitted diseases was factors affecting both women's knowledge and their attitude. Having knowledge on cervical cancer was factor affecting attitude towards screening services. Provision of information, education, and counseling about the disease and screening service are mandatory to address their knowledge gap and to improve women's attitude towards screening service.

Keywords: Women aged 30-49 years, Knowledge, Attitude, Ethiopia

\footnotetext{
* Correspondence: alexbishaw@gmail.com

'Department of Reproductive Health, Institute of Public Health, College of

Medicine and Health Science, University of Gondar, 196 Gondar, Ethiopia

Full list of author information is available at the end of the article
} 


\section{Plain English summary}

Screening services for cervical pre-cancerous lesions are currently available for all women aged 30-49 years at public hospitals in Ethiopia. Though women's knowledge and their attitude are determinants for the uptake the screening service, there is limited information on these. Therefore, this study aimed to assess the comprehensive knowledge of cervical cancer, attitudes towards the screening, and associated factors among women aged 30-49 years at Finote Selam town, northwest Ethiopia.

A total of 1137 women participated in this study. Nearly one third, $30.3 \%$ of the women had comprehensive knowledge on cervical cancer, and $58.1 \%$ had a favorable attitude towards cervical cancer screening. Having college and above education, knowing someone with cervical cancer, and having a history of sexually transmitted diseases were significantly associated with comprehensive knowledge of cervical cancer. Meanwhile, college and above educational status, knowing someone with cervical cancer, and having comprehensive knowledge of cervical cancer were positively associated with favorable attitude towards cervical cancer screening. Therefore we recommended that provision of information, education, and counseling about the disease and screening service are mandatory to address the knowledge gap and to improve women's attitude towards screening services.

\section{Background}

Despite the fact that cervical cancer is preventable, it is reported that there were 485,000 cervical cancer cases and 236,000 deaths of women due to cervical cancer in 2013 worldwide [1]. Almost $87 \%$ of the deaths occurred in less developed regions, it was the second most commonly diagnosed cancer and the third leading cause of cancer death among females in less developed countries [2].

East Africa has the highest sub- regional incidence of cervical cancer in which the age standardised rate is 42.7 per 100,000 women, followed by Southern Africa with 31.5 per 100,000 women [3]. In Ethiopia, an estimated 7095 new cervical cancer cases were diagnosed, and 4732 die annually from it in 2012 [4]. New cases of cancer were diagnosed in the Black Lion specialized Hospital data set between 1997 and 2012, and the result revealed that $31.8 \%$ were cervical cancer patients [5].

The large geographic variations in cervical cancer rates reflect the presence of differences in the accessibility of screening service because the presence of screening service detects precancerous lesion and helps early initiation of treatment of the lesion before it progresses to cancer stage [6]. A population survey indicates the average cervical cancer screening in developing countries is $19 \%$ while it is $63 \%$ in developed countries and ranging from $1 \%$ to $73 \%$ respectively [7]. A meta-analysis noted that the risk of dying from cervical cancer was 35\% lower among women invited to screening with cytology testing than among women who were not offered screening services [8].

Having knowledge on cervical cancer and it's screening is associated with the uptake of services [9], favourable attitudes towards cervical cancer screening is also associated with the uptake of screening services $[10,11]$. Cervical cancer screening helps to detect pre-cancerous lesions before it advances to a cancerous stage which in turn reduces its related mortality rates. In Ethiopia, screening services for cervical pre-cancerous lesion is available for all women aged 30-49 years at public health institutions [12]. Women's knowledge on cervical cancer and their attitude for screening determine the uptake of service [13]. However, evidence on women's knowledge of cervical cancer and their attitude towards screening at the community level is very limited in Ethiopia. Therefore, a community based study was conducted to assess knowledge of cervical cancer, attitude towards its screening and associated factors among women aged 30-49 years at Finote Selam town, northwest Ethiopia.

\section{Methods \\ Study design and setting}

A community based cross-sectional study was conducted from March 30, to April 15, 2017 at Finote Selam town, northwest Ethiopia. Finote Selam town is located in West Gojam Administration Zone of the Amhara Regional State, northwest Ethiopia. According to the population projection of Ethiopia for all regions at woreda level 2017, the total population of the town is estimated to be 38,399 . Out of these, 19,923 are male and $18,476 \mathrm{fe}-$ male [14]. At the moment, the town has five kebeles, the smallest administrative units. The total number of households was 5530.

Finote Selam town has one primary hospital, one public health centre, and four private clinics. Since April 2016, cervical cancer screening service and treatment for pre cervical lesion has been offered to women aged 30 to 49 years. For this study, all women aged $30-49$ years living in Finote Selam town were the source population.

\section{Sample size and sampling procedure}

The sample size was determined using single population proportion formula $\left(\mathrm{n}=(\mathrm{Z} \alpha / 2)^{2} \mathrm{p}(1-\mathrm{p}) / \mathrm{d}^{2}\right)$ with the following assumptions: $44.6 \%$ proportion of sufficient knowledge on cervical cancer, and $42.1 \%$ favourable attitude towards screening on the bases of a previous study done in Dessie, Ethiopia [11], A 95\% level of confidence, 5 and $4 \%$ degree of precision for knowledge, and attitude respectively, two design effect, and 5\% none response rate were used. The sample sizes calculated were 797 and 1224 for knowledge and attitude, respectively. Sample size was also calculated for factors using EPI info version 
7 considering a 95\% level of confidence, and $80 \%$ power. However, the sample size for factors were found less than the sample size calculated for the outcome variables (knowledge and attitude). So, we considered 1224 as sample size for this study.

\section{Operational definitions \\ Having comprehensive knowledge on cervical cancer}

Refers to women who answered mean value and above of the twenty knowledge questions [15].

\section{Favourable attitude towards cervical cancer screening}

refers to women who answered mean and above of the six attitude questions Six attitude questions were used with five likert scale measurement: strongly disagree, disagree, neither agree nor disagree, agree, and strongly agree. A woman who scored mean value and above was considered as having a favourable attitude.

\section{Data collection instrument and process}

The data collection tool (questionnaire) was developed by reviewing literature [11, 15-17]. The questionnaire was first prepared in English and translated to Amharic then back to English to ensure consistency. The questionnaire carried socio-demographic characteristics, risk of exposure to cervical cancer and reproductive health service utilization, knowledge and attitude assessing questions. The attitude questions were developed using a five level likert scale. Six female diploma and two BSc degree graduated midwives were recruited for data collection, and supervision, respectively. Face-to-face interviewer administered questionnaire was used.

To ensure data quality, a two day training was given to data collectors and supervisors. The questionnaire was pre-tested on 42 women who were living outside the selected kebeles to check the response, the clarity, and the appropriateness of the questions. The data collection and supervision were overseen by researchers to ensure completeness and consistency of data.

\section{Data analysis}

The data were checked for completeness, coded manually, and entered into EPI-info version 7 and transferred to SPSS version 20 for analysis. Descriptive statistics were expressed in numerical value, mean, standard deviation, and percentages. Both bivariate and multivariable logistic regression analyses were done to identify variables associated with knowledge on cervical cancer, and attitude towards screening.Variables with less than 0.2 $P$-value, in the bivariate analysis were entered into multivariable analysis to control potential confounders. Hosmer-Lemeshow goodness of fit test was used to check the model fitness. Adjusted odds ratio with 95\% confidence interval was used to determine the presence, degree, and direction of association between covariates and the outcome variable.

\section{Results}

Socio demographic characteristics participants

A total of 1137 women participated in this study giving a response rate of $93.7 \%$. Ten questionnaires were incomplete. The mean age of the participants was 37.4 years (SD \pm 5.72 years). The majority (92.2\%) of study participants were Orthodox Christians, two-thirds (66.4\%) of the women were married, and nearly half 513(45.1\%) had no formal education. Out of the total participants, 530(46.6\%) reported that their main occupation was household activities. One quarter (24.5\%) of the participants had less than 23 US\$ family average monthly income, and $37.7 \%$ had more than 68 US \$ (Table 1).

\section{Women's risk of exposure and reproductive health services utilization}

More than half of the women, 615 (54.1\%), had the first sexual intercourse at the age of 16 or below. The mean age of the first sexual intercourse of the women was 16.4 years $(\mathrm{SD} \pm 3.29$ years). More than two-thirds of participants, 788(69.3\%), had two or more sexual partners in their life time. One thousand sixteen (89.4\%) women had history of at least one pregnancy and 1002 $(88 \%)$ history of at least one child birth. Among women who had history of pregnancy, 579 (57\%) had antenatal follow up during their last pregnancy. Out of the total participants 163(14.3\%) had at least one history of abortion in their life time. Approximately three-fourths of the women, $830(73 \%)$ used modern contraceptive in their life time, and $14.6 \%$ had history of oral contraceptive use. During data collection, 590(51.9\%) were using modern contraceptive. Only 49 (4.3\%) of the women reported that they had history of sexually transmitted disease.(Table 2) Sixty-four (5.6\%) participants reported that they knew persons with cervical cancer.

\section{Knowledge about cervical cancer}

The awareness of the women on cervical cancer was $34.3 \%$ (95\%CI: 31.7, 36.9). The major source of information was the mass media for 163(41.7\%), family, friends, and neighbors for $160(41 \%)$. The number of the participants who listed at least one symptom of cervical cancer was $240(21.1 \%)(95 \% \mathrm{CI}: 18,24)$. The most commonly mentioned symptom for cervical cancer was intermenstrual bleeding 99 (8.7\%). Most of the participants $897(78.9 \%)$ did not know any symptom of cervical cancer. Slightly less than a quarter, 264(23.2\%) (95\%CI: 19.6,26), of the participants identified at least one risk factor for the diseases. The most commonly mentioned, 138 (12.1\%), risk factor for cervical cancer was multiple sexual partners. 
Table 1 Socio-demographic characteristics of study participants in Finote Selam town, northwest Ethiopia, 2017

\begin{tabular}{|c|c|c|c|c|c|c|c|}
\hline \multirow[t]{2}{*}{ Characteristics } & \multirow{2}{*}{$\begin{array}{l}\text { Frequency } \\
n=1137(\%)\end{array}$} & \multicolumn{2}{|c|}{ Compressive knowledge } & \multirow[t]{2}{*}{$P$-value } & \multicolumn{2}{|c|}{ Attitude } & \multirow[t]{2}{*}{$P$-value } \\
\hline & & No & Yes & & No & Yes & \\
\hline \multicolumn{8}{|l|}{ Age } \\
\hline $30-34$ & $372(32.7)$ & 249 & 123 & 0.003 & 163 & 209 & 0.142 \\
\hline $35-39$ & $366(32.2)$ & 241 & 125 & 0.001 & 130 & 236 & 0.001 \\
\hline $40-44$ & $200(17.6$ & 145 & 55 & 0.137 & 83 & 117 & 0.80 \\
\hline $45-49$ & 199(17.5) & 157 & 42 & & 100 & 99 & \\
\hline \multicolumn{8}{|l|}{ Religion } \\
\hline Orthodox & 1048(92.2) & 737 & 351 & & 449 & 599 & \\
\hline Muslim & $81(7.1)$ & 51 & 30 & 0.16 & 25 & 56 & 0.037 \\
\hline Protestant & $8(0.7)$ & 4 & 4 & 0.22 & 2 & 6 & 0.322 \\
\hline \multicolumn{8}{|l|}{ Marital status } \\
\hline Married & $755(66.6)$ & 29 & 28 & 0.001 & 13 & 44 & 0.001 \\
\hline Divorced & $221(19.4)$ & 523 & 232 & 0.73 & 301 & 454 & 0.50 \\
\hline Windowed & 104(9.2) & 159 & 62 & 0.257 & 110 & 111 & 0.970 \\
\hline Single & $57(5)$ & 81 & 23 & & 52 & 52 & \\
\hline \multicolumn{8}{|l|}{ Educational status } \\
\hline No formal education & $513(45.1)$ & 455 & 58 & & 276 & 237 & \\
\hline Primary school & $295(26)$ & 220 & 75 & .000 & 124 & 171 & .001 \\
\hline Secondary school (9-12) & $198(14)$ & 81 & 117 & .000 & 53 & 145 & .000 \\
\hline College/university & $131(11.5)$ & 36 & 95 & .000 & 23 & 108 & .000 \\
\hline \multicolumn{8}{|l|}{ Occupation } \\
\hline Household activities & $530(46)$. & 434 & 96 & & 270 & 260 & \\
\hline Self employed & $254(22.3)$ & 166 & 88 & .000 & 87 & 167 & 0.000 \\
\hline Farmerand daily worker & $169(15)$ & 132 & 37 & 0.27 & 74 & 95 & 0.11 \\
\hline Government employed & $98(8.6)$ & 22 & 76 & 0.000 & 16 & 82 & 0.000 \\
\hline Private employee & $73(6.4$ & 31 & 42 & 0.000 & 27 & 46 & 0.027 \\
\hline Student & $13(1.1)$ & 7 & 6 & 0.017 & 2 & 11 & 0.024 \\
\hline \multicolumn{8}{|c|}{ Family average monthly income ${ }^{a}$} \\
\hline$<22$ & $278(24.5)$ & 234 & 61 & & 142 & 153 & \\
\hline $22-45$ & $344(30.3)$ & 288 & 79 & 0.276 & 171 & 196 & 0.693 \\
\hline $45-68$ & $85(7.5)$ & 47 & 24 & .020 & 30 & 41 & 0.373 \\
\hline$>68$ & $430(37.7)$ & 223 & 181 & .000 & 133 & 271 & .000 \\
\hline
\end{tabular}

Out of participants, 259 (22.8\%) (95\%CI: 20, 27.3), mentioned at least one prevention methods of cervical cancer. Avoiding multiple sexual partners, 181 (15.9\%), and early sexual intercourse, 60 (5.3\%), were the most commonly mentioned ways of prevention. Nearly three-fourths participants, 866 (76.2\%) reported that cervical cancer could not be treated even if diagnosed early stage. With regard to treatment of the diseases, surgery was the most frequently mentioned method by $175(15.4 \%)$ followed by chemotherapy pointed out by $167(14.7 \%$ ) (Table 3). About 30.3\% (95\%CI: 27.7, 32.9) of the participants had comprehensive knowledge of cervical cancer (Fig. 1).

\section{Women's attitude towards cervical cancer screening}

The majority of the women, 1046 (92\%), agreed on consulting a health care professional during intermenstrual bleeding. About half of the participants, 586 (51.5\%), agreed that any sexually active woman is at risk of acquiring cervical cancer, and 429(37.8\%) participants agreed that cervical cancer could be transmitted sexually. Two-thirds 744 (65.4\%) agreed that pre-cervical cancer lesion screening helped to prevent cervical cancer. Among respondents, 699 (61.5\%) stated that pre cervical cancer screening was not harmful. Significant proportions of women (87\%) agreed to screen for the future if screening was free of charge. The proportion of women who had 
Table 2 Women's risk of exposure to cervical cancer and reproductive health services utilization in Finote Selam town, northwest Ethiopia

\begin{tabular}{|c|c|c|c|}
\hline Characteristics & & Frequency & Percent \\
\hline Age at first sexual intercourse & $\begin{array}{l}<=16 \text { years } \\
>16 \text { years }\end{array}$ & $\begin{array}{l}615 \\
522\end{array}$ & $\begin{array}{l}54.1 \\
45.9\end{array}$ \\
\hline Life time number of sexual partners & $\begin{array}{l}\text { One } \\
\text { Two and more }\end{array}$ & $\begin{array}{l}349 \\
788\end{array}$ & $\begin{array}{l}30.7 \\
69.3\end{array}$ \\
\hline History of pregnancy & $\begin{array}{l}\text { Yes } \\
\text { No }\end{array}$ & $\begin{array}{l}1016 \\
121\end{array}$ & $\begin{array}{l}89.4 \\
10.6\end{array}$ \\
\hline History of child birth & $\begin{array}{l}\text { Yes } \\
\text { No }\end{array}$ & $\begin{array}{l}1002 \\
135\end{array}$ & $\begin{array}{l}88 \\
12\end{array}$ \\
\hline ANC during the last pregnancy $(N=1016)$ & $\begin{array}{l}\text { Yes } \\
\text { No }\end{array}$ & $\begin{array}{l}579 \\
437\end{array}$ & $\begin{array}{l}57 \\
43\end{array}$ \\
\hline Abortion experience during the life time & $\begin{array}{l}\text { Yes } \\
\text { No }\end{array}$ & $\begin{array}{l}163 \\
974\end{array}$ & $\begin{array}{l}14.3 \\
85.7\end{array}$ \\
\hline PNC after the last child birth $(N=1002)$ & $\begin{array}{l}\text { Yes } \\
\text { No }\end{array}$ & $\begin{array}{l}259 \\
743\end{array}$ & $\begin{array}{l}25.8 \\
74.2\end{array}$ \\
\hline $\begin{array}{l}\text { Ever used modern contraceptive method } \\
\text { in the life time }\end{array}$ & $\begin{array}{l}\text { Yes } \\
\text { No }\end{array}$ & $\begin{array}{l}830 \\
307\end{array}$ & $\begin{array}{l}73 \\
27\end{array}$ \\
\hline Modern contraceptive use during data collection & $\begin{array}{l}\text { Yes } \\
\text { No }\end{array}$ & $\begin{array}{l}590 \\
547\end{array}$ & $\begin{array}{l}51.9 \\
48.1\end{array}$ \\
\hline Self reported history of STI during life time & $\begin{array}{l}\text { Yes } \\
\text { No }\end{array}$ & $\begin{array}{l}49 \\
1088\end{array}$ & $\begin{array}{l}4.3 \\
95.7\end{array}$ \\
\hline Knew person with cervical cancer & $\begin{array}{l}\text { Yes } \\
\text { No }\end{array}$ & $\begin{array}{l}62 \\
1075\end{array}$ & $\begin{array}{l}5.6 \\
94.4\end{array}$ \\
\hline
\end{tabular}

Abbreviation: ANC Ante Natal Care, PNC Post Natal Care, STI Sexually Transmitted Infections

favorable attitude towards cervical cancer screening was 58.1\% (95\% CI: 55, 62.2) (Fig. 1).

\section{Factors associated with women's comprehensive knowledge on cervical cancer}

The bivariate analysis showed that socio-demographic variables, such as age, marital status, education, occupation, average family monthly income, knowing anyone who had cervical cancer, and reproductive history including number of life-time sexual partner, gravidity, ANC service utilization, parity, PNC service utilization, ever use of modern contraceptives, currently using contraceptives and history of STD were significantly associated with the comprehensive knowledge score of cervical cancer at $P$-value of less than 0.2 . In the multi variable analysis, educational status, knowing someone with cervical cancer, and history of STD remained significant.

Participants who attended primary school were nearly two times $(\mathrm{AOR}=1.65,95 \% \mathrm{CI}: 1.05,2.59)$ more likely to be knowledgeable on cervical cancer than those who did not attend formal education. Women who attend secondary school (grade 9-12) were more than five times $(\mathrm{AOR}=5.59,95 \% \mathrm{CI}: 3.25,9.63)$ more likely to be knowledgeable than those who did not have formal education. Study participants who attended college/university were seven times (AOR $=7.21,95 \% \mathrm{CI}$ : 3.41,15.29) more likely to be knowledgeable than those who did not have formal education. Women who knew someone with cervical cancer were five times $(\mathrm{AOR}=5.38,95 \% \mathrm{CI}: 2.38$, 12.15) more likely to be knowledgeable on cervical cancer compared to those who did not know cancer cases.

In the present study, women who had history of sexually transmitted diseases (STD) were nearly three times (AOR $=2.75,95 \%$ CI: $1.24,6.04)$ more likely to be knowledgeable than those who had no history of STD (Table 4).

\section{Factors associated with a ttitude towards cervical cancer screening}

According to the bivariate analysis, seven sociodemographic variables, age, religion, marital status, education, occupation, average family monthly income, knowing someone with cervical cancer, including nine other variables were significantly associated with attitude to cervical cancer screening at $P$-value of less than 0.2 . In the multivariable analysis, three variables, such as educational status, knowing someone with cervical cancer and comprehensive knowledge about the diseases became significant with attitude towards cervical cancer screening at a P-value of less than 0.05 .

Participants who attended college/university were 2.56 times $(\mathrm{AOR}=2.56,95 \% \mathrm{CI}: 1.14,5.69)$ more likely to have a favorable attitude towards screening than those who did not attend formal education. Women who knew someone who had cervical cancer were three times $(\mathrm{AOR}=3.24,95 \% \mathrm{CI}: 1.14,9.15)$ more likely to have a favorable attitude towards cervical cancer screening. 
Table 3 Knowledge of participants of cervical cancer by components among aged 30-49 years women in Finote Selam town, northwest Ethiopia, 2017

\begin{tabular}{|c|c|c|}
\hline Variables & $\begin{array}{l}\text { Frequency } \\
n=1137\end{array}$ & Percent \\
\hline \multicolumn{3}{|l|}{ Symptom of cervical cancer } \\
\hline Inter menstrual bleeding & 99 & 8.7 \\
\hline Foul smelling vaginal discharge & 95 & 8.4 \\
\hline Pain during sexual intercourse & 69 & 6.1 \\
\hline $\begin{array}{l}\text { Vaginal bleeding during and } \\
\text { after sexual intercourse }\end{array}$ & 20 & 1.8 \\
\hline \multicolumn{3}{|l|}{ Risk factors of cervical cancer } \\
\hline Multiple sexual partners & 138 & 12.1 \\
\hline Early sexual intercourse & 67 & 5.9 \\
\hline HIV infection & 43 & 3.8 \\
\hline HPV infection & 40 & 3.5 \\
\hline Others & 4 & 0.4 \\
\hline \multicolumn{3}{|l|}{ Prevention of cervical cancer } \\
\hline Avoiding multiple sexual partners & 181 & 15.9 \\
\hline Avoiding early sexual intercourse & 60 & 5.3 \\
\hline Avoiding pregnancies & 24 & 2.1 \\
\hline Screening for pre-cervical cancer lesions & 22 & 1.9 \\
\hline Vaccination of HPV & 4 & 0.4 \\
\hline $\begin{array}{l}\text { Cervical cancer can be treated if diagnosed } \\
\text { early stage }\end{array}$ & 271 & 23.8 \\
\hline \multicolumn{3}{|l|}{ Treatment for cervical cancer } \\
\hline Surgery & 175 & 15.4 \\
\hline Chemotherapy & 167 & 14.7 \\
\hline Radiotherapy & 15 & 1.3 \\
\hline
\end{tabular}

Abbreviation: HPV human papiloma virus

Note: Others $=$ multiparty and oral contraceptive use

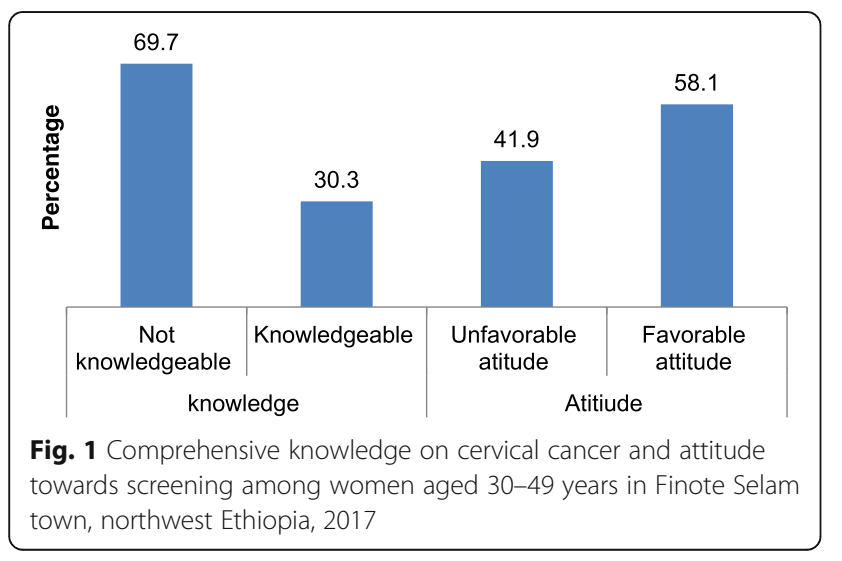

Women who had comprehensive knowledge of cervical cancer were three times $(\mathrm{AOR}=3.00,95 \% \mathrm{CI}: 1.97,4.29)$ more likely to have a favorable attitude towards cervical cancer screening than their counterparts (Table 5).

\section{Discussion}

Knowledge of cervical cancer and attitude towards its screening are essential for the prevention of the disease. The current study was conducted to determine women's comprehensive knowledge on cervical cancer, attitude towards pre-cervical cancer screening and associated factors.

The study revealed that nearly one-third, 30.3\% (95\%CI: 27.2-32.9), of participants had comprehensive knowledge on cervical cancer. This finding is comparable with that of a community based study conducted in Gondar (31\%), Ethiopia, among women aged 15 years and above [15]. This finding is higher than the finding $25 \%$ reported from Addis Ababa [18]. The possible reason for difference might be that the researchers used only 13 questions and 7/13 was used as the cutoff point to determine knowledge in the previous study. However, our result is lower than the finding reported by a community-based study in Uganda which noted 55\% [19]. The possible reason for the difference from the study done in Uganda could be the variation in educational status between the two study populations. The majority of the participants in the Ugandan study completed primary school unlike ours in which nearly half of participants did not have formal education.

Ours study showed that $58.1 \%$ (95\% CI: $55,62.2$ ) of the women had favourable attitude towards cervical cancer screening. This result was better than that of a study done in Dessie, Ethiopia which documented 42.1\% [11]. The gap between our study and that of Dessie might be the high proportion of single (unmarried) participants in the Dessie study. There is evidence that single women have less favourable attitude towards screening [16]. However, the result is lower than the finding of a hospital-based study in India which reported 76\% [16]. The difference between our and the study in India might be the study setting; hospitalized women might have high health seeking behaviour and better access to information. Our finding was also lower than that of a study conducted among market women in Nigeria noted $80.4 \%$ had favourable attitude towards screening [20]. The difference might be that in the Nigeria study the participants were shop owners/attendants aged 15 years and above, most of them with higher educational status.

In this study, educational status was positively associated with women's comprehensive knowledge on cervical cancer. Women who have primary, secondary and college/ university education were more likely to have better knowledge on cervical cancer than those who did not have 


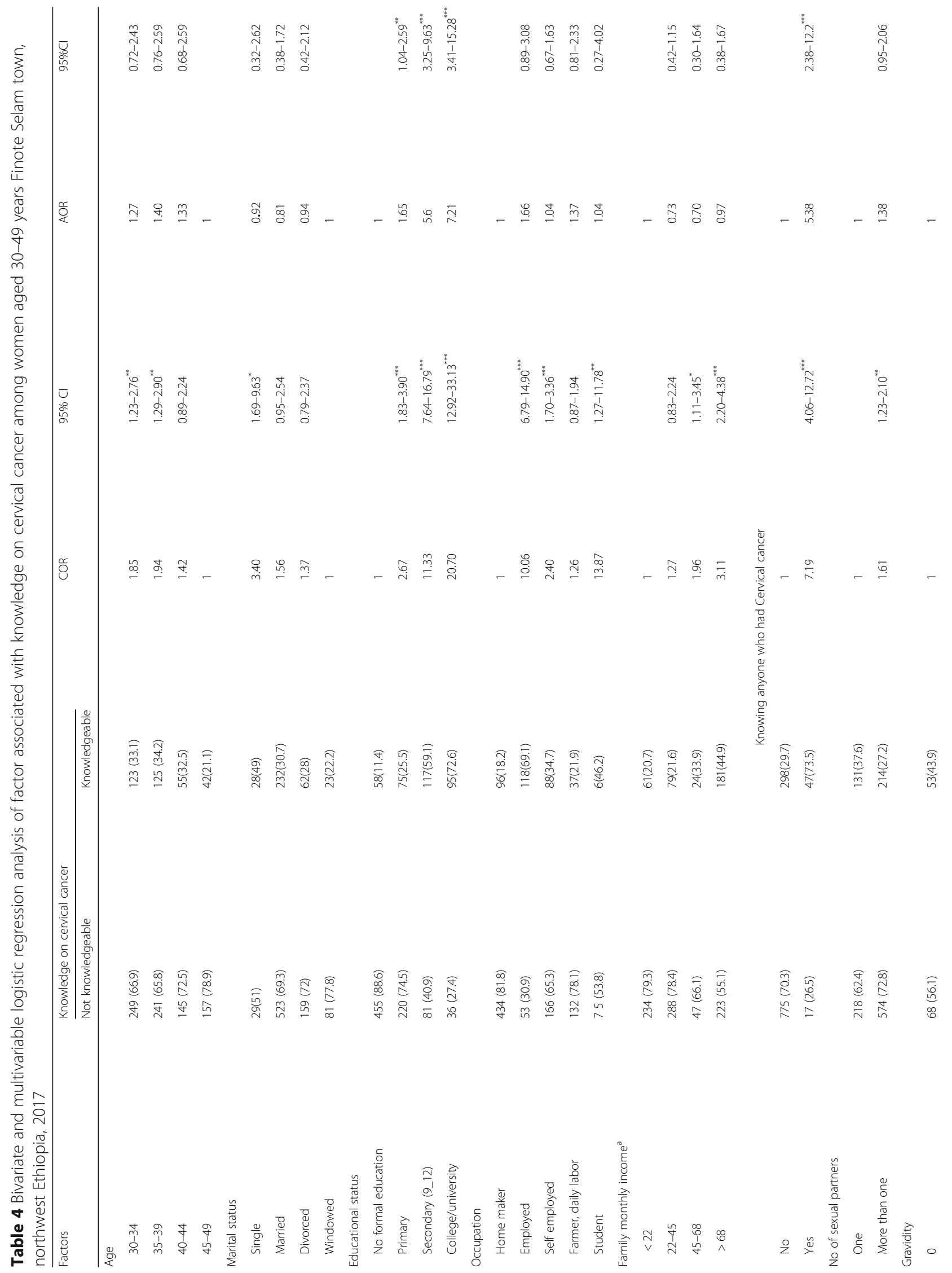




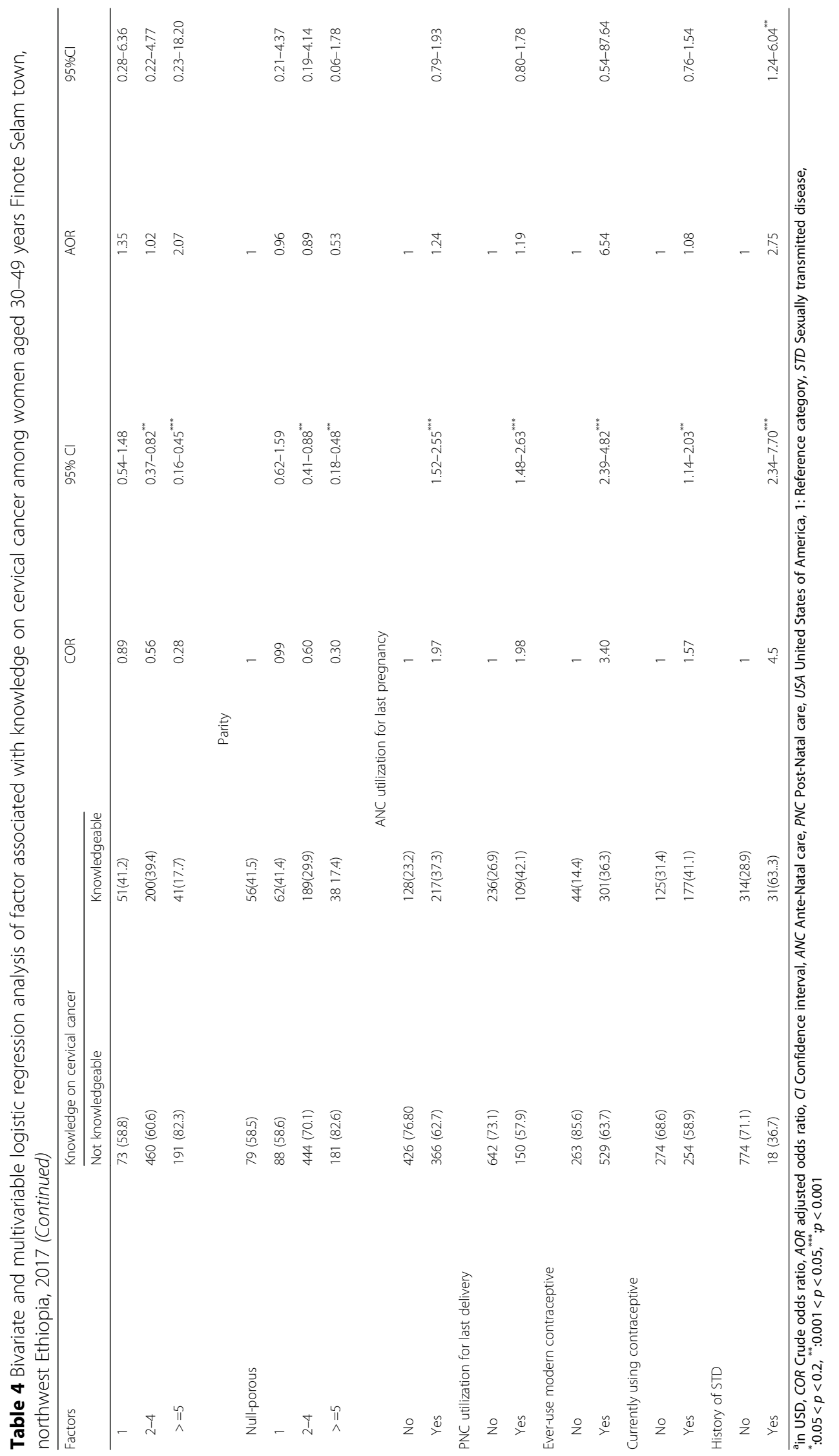




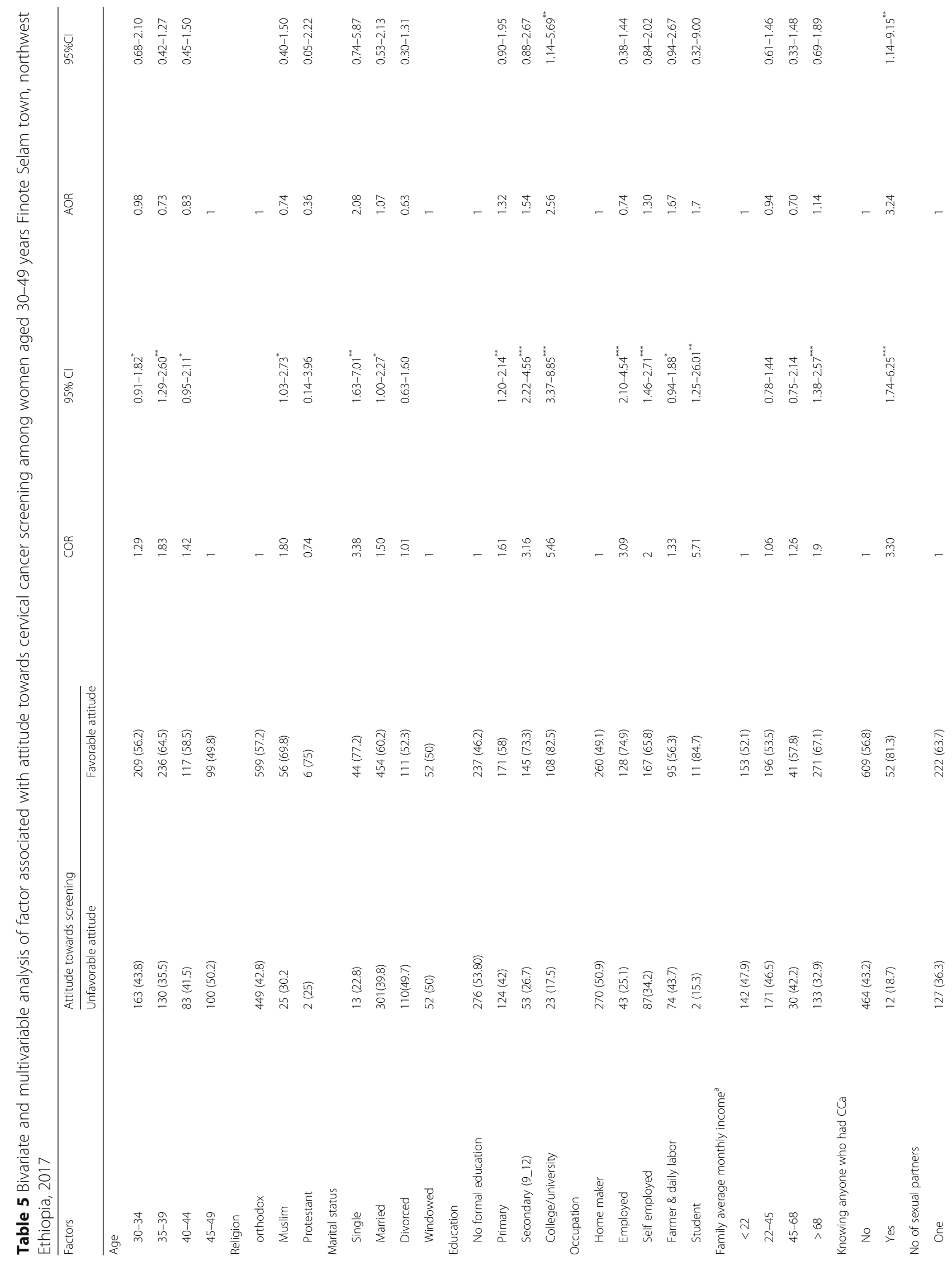




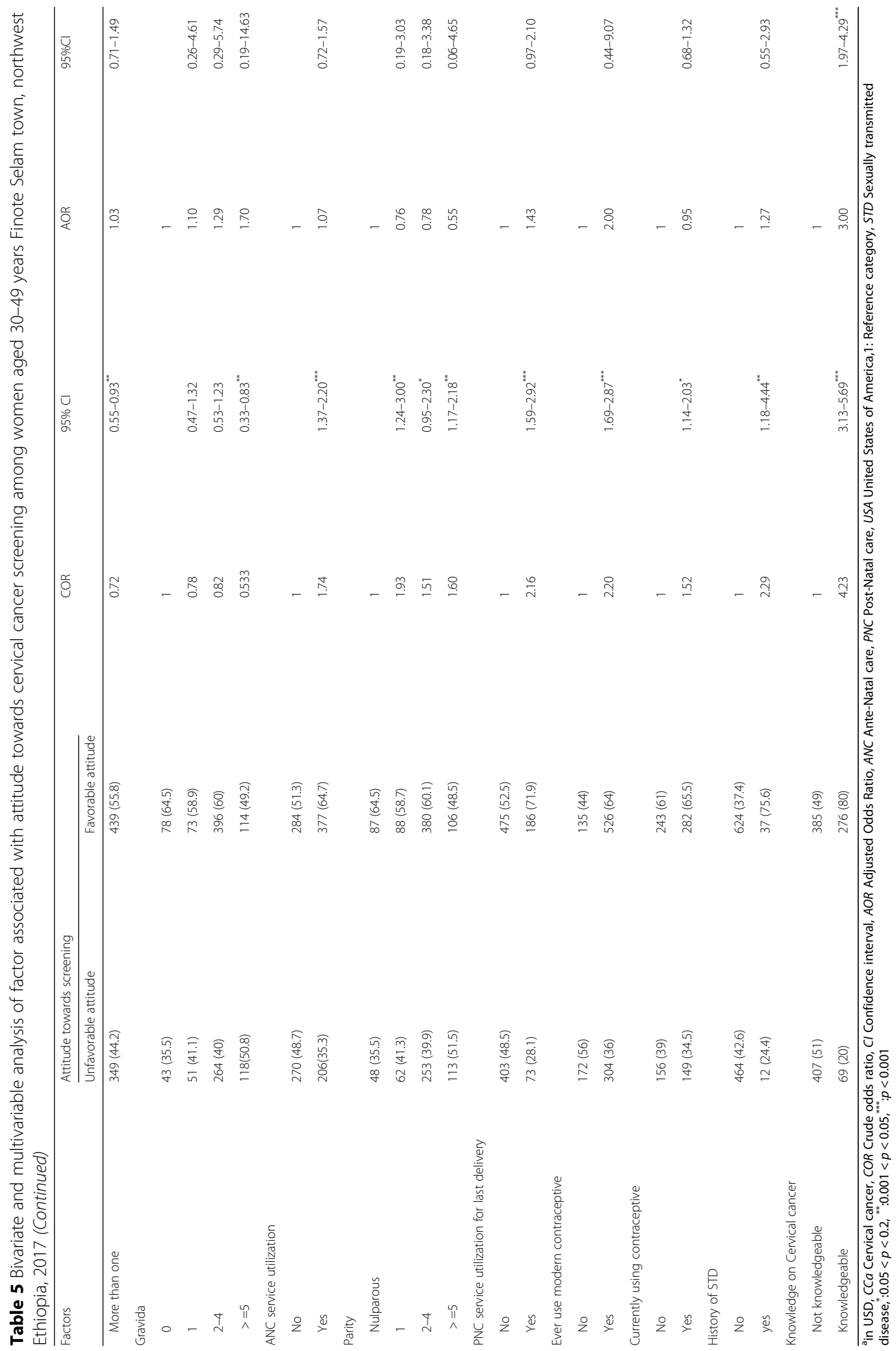


formal education. Studies in the Democratic Republic of Congo [10], India [16], and Dessie, Ethiopia [11], reported similar findings. Similarly, in this study, it was found that educational status of women had a significant association with attitude towards cervical cancer screening. In the present study, women who had college and above educational status were more than two times more likely to have favorable attitude towards cervical cancer screening. Similar results were found by studies conducted in Eastern Uganda [19], and Addis Ababa [18].

The present study identified that the participants who knew someone with cervical cancer were five times more likely to be knowledgeable on cervical cancer than those who didn't know someone with cervical cancer. Studies conducted in Gondar [15], and Kenya [21] had similar findings. Our study revealed that women who knew someone who had cancer were 3.24 times more likely to have favorable attitude towards cervical cancer screening $(\mathrm{AOR}=3.24,95 \% \mathrm{CI}: 1.14,9.15)$.

Our finding showed that women who had history of STD were nearly three times more likely to be knowledgeable on cervical cancer than those who had not. A similar finding was reported by a study done on Asian Maldives [22]. This might be because of women who had STD might have contact with health professionals to get treatment for the disease during which they might be advised/counselled about the risks of unprotected sex, including the risk of viral infections, such as HIV, and the human papiloma virus plus their consequences and means of prevention. Thus, this communication might help them get information on cervical cancer. A study conducted in rural Kenya identified that family planning service utilization was positively associated with knowledge on cervical cancer [9]. In our study, no significant association was observed between knowledge on cervical cancer and obstetric service related variables such as ANC, family planning and post-natal service utilization. This may suggest that women who utilize maternal health services do not receive information on cervical cancer.

The finding in this study showed that women who had comprehensive knowledge of cervical cancer were three times more likely to have favorable attitude towards cervical cancer screening as compared to their counterparts. Previous studies done in Nepal [23], and a health facility-based study in Dessie Ethiopia [11], reported a similar finding. This shows that women who have adequate knowledge on cervical cancer might understand the nature disease (causes, symptoms, preventions, and treatments), and the benefits of screening which in turn make them have positive attitude towards screening. Since this study was conducted in urban setting that could not generalize for rural women. This might be the potential limitation of this study. Additionally, one of the independent variables we considered was history of sexually transmitted diseases that might be exposed for social desirability bias. However, the authors tried to minimize this potential bias by providing adequate information for the study participants about the importance of telling the truth and confidentiality nature of the research.

\section{Conclusion}

In this study, it was identified that women's knowledge on cervical cancer was low, despite the high incidence of the disease in Ethiopia. Relatively, a large proportion of the study participants in this study had favorable attitude towards cervical cancer screening. Attending primary, secondary school and college, knowing someone who had cervical cancer and history of STD were factors associated to comprehensive knowledge on cervical cancer.

Attended college and above, knowing someone who had cervical cancer, and having comprehensive knowledge on cervical cancer were important factors for having favorable attitude towards cervical cancer screening. There is clear need for information sharing on cervical cancer, including its screening targeting women with less educated. Educational campaign on the disease and screening,involving the mass media in providing information to the women on cervical cancer, including screening service availability when the women visit health facilities for reproductive services are proposed.

\section{Abbreviations \\ ANC: Ante Natal care; AOR: Adjusted Odds Ratio; Cl: Confidence Interval; PNC: Post Natal care; SD: Standard Deviation; SPSS: Statistical Package for Social Sciences; STD: Sexually transmitted disease}

\section{Acknowledgements}

We would like to extend our heart full gratitude to University of Gondar, Institute of public health for giving ethical clearance and the financial support for this study. Our heart full tank is extended to the study participants for their time and willingness to participate and to data collectors and supervisor for their commitment. Our appreciation also extended for Finote Selam town health office for their cooperativeness and provision of supportive letters.

\section{Funding}

University of Gondar sponsored this study. However, it has no role in manuscript preparation and publication.

\section{Availability of data and materials}

All the required data are available in the main document.

\section{Authors' contributions}

ABG brought the idea. $A B G, A A G$, and $T A$ equally contributed on proposal development, data collection process, data management and analysis, and write up. All authors have read and approved the manuscript.

\section{Ethics approval and consent to participate}

Ethical approval was obtained from Institutional Review Board of the University of Gondar, Institute of Public Health. Participants were informed about the confidentiality of information and it was maintained by excluding personal identifiers from the data collection form. Verbal informed consent was obtained from every study participants before data collection. Participants were informed that participation was voluntary and as it was their right not to participate or withdraw at any time if they were not comfortable. 


\section{Consent for publication}

It is not applicable since it is a cross-sectional study.

\section{Competing interests}

All authors declared that they have no any competing interest.

\section{Publisher's Note}

Springer Nature remains neutral with regard to jurisdictional claims in published maps and institutional affiliations.

\section{Author details}

${ }^{1}$ Department of Reproductive Health, Institute of Public Health, College of Medicine and Health Science, University of Gondar, 196 Gondar, Ethiopia. ${ }^{2}$ Department of Health Education and Behavioral Sciences, Institute of Public Health, College of Medicine and Health Sciences, University of Gondar, Gondar, Ethiopia.

\section{Received: 27 October 2017 Accepted: 30 January 2018}

\section{Published online: 14 February 2018}

\section{References}

1. Fitzmaurice C, Dicker D, Pain A, Hamavid H, Moradi-Lakeh M, Maclntyre MF, et al. The global burden of cancer 2013. JAMA Oncol. 2015;1:505-27.

2. Ferlay JSI, Dikshit R, Eser S, Mathers C, Rebelo M, et al. Cancer incidence and mortality worldwide: sources, methods and major patterns in GLOBOCAN 2012. Int J Cancer. 2015;136:E359-86.

3. UNFPA: Africa cervical cancer multi indicator incidence\& mortality score card 2014.

4. Bruni L, Barrionuevo-Rosas L, Albero G, Serrano B, Mena M, Gómez D, Muñoz J, Bosch FX, de Sanjosé S. Human Papillomavirus and related diseases in Ethiopia. Summary report december 2016. ICO Information Centre on HPV and Cancer (HPV Information Centre). 2016. https://www. hpvcentre.net/statistics/reports/XWX.pdf.

5. Abate SM. Trends of cervical cancer in Ethiopia 2015. Cervical Cancer. 2015; 1:103.

6. Torre LA, Bray F, Siegel RL, Ferlay J, Lortet-Tieulent J, Jemal A. Global cancer statistics, 2012. CA Cancer J Clin. 2015;65:87-108.

7. Gakidou E, Nordhagen S, Obermeyer Z. Coverage of cervical cance screening in 57 countries: low average levels and large inequalities. PLoS Med. 2008;5:e132.

8. Peirson L, Fitzpatrick-Lewis D, Ciliska D, Warren R. Screening for cervical cancer: a systematic review and meta-analysis. 2013;2:35. https://doi.org/10 1186/2046-4053-2-35.

9. Rosser Jl, Njoroge B, Huchko MJ. Knowledge on cervical cancer screening and perception of risk among women attending outpatient clinics in rural Kenya. Int J Gynaecol Obstet. 2015;128:211-5.

10. Ali-Risasi C, Mulumba P, Verdonck K, Vanden Broeck D, Praet M. Knowledge, attitude and practice about cancer of the uterine cervix among women living in Kinshasa, the Democratic Republic of Congo. BMC Womens Health. 2014; 14:30.

11. Andargie A, Reddy PS. Knowledge, attitude, practice and associated factors of cervical cancer screening among women in Dessie referral hospital and Dessie health center, Northeast Ethiopia. Glob J Res Anal. 2016;4

12. Federal Ministry Of Health Ethiopia: National Cancer Control Plan 20162020. October 2015.

13. Bayu $H$, Berhe $Y$, Mulat A, Alemu A. Cervical cancer screening service uptake and associated factors among age eligible women in Mekelle zone, northern Ethiopia, 2015 a community based study using health belief model. PLoS One. 2015;11:e0149908.

14. Population Projection of Ethiopia for All Regions at Wereda Level 2017 August 2013.

15. Getahun F, Mazengia F, Abuhay M, Birhanu Z. Comprehensive knowledge about cervical cancer is low among women in Northwest Ethiopia. BMC Cancer. 2013;13:2.

16. Bansal AB, Pakhare AP, Kapoor N, Mehrotra R, Kokane AM. Knowledge, attitude, and practices related to cervical cancer among adult women: a hospital-based cross-sectional study. J Nat Sci Biol Med. 2015:6:324.

17. Mitiku I, Tefera F. Knowledge on cervical cancer and associated factors among 15-49 year old women in Dessie town, Northeast Ethiopia. PLoS One. 2016;11:e0163136.
18. Belete $\mathrm{N}$, Tsige $\mathrm{Y}$, Mellie $\mathrm{H}$. Willingness and acceptability of cervical cancer screening among women living with HIV/AIDS in Addis Ababa, Ethiopia: a cross sectional study. Gynecol Oncol Res Prac. 2015;2:6.

19. Mukama T, Ndejjo R, Musabyimana A, Halage AA, Musoke D. Women's knowledge and attitudes towards cervical cancer prevention: a cross sectional study in eastern Uganda. BMC Womens Health. 2017;17:9.

20. Ahmed SA, Sabitu K, Idris SH, Ahmed R. Knowledge, attitude and practice of cervical cancer screening among market women in Zaria, Nigeria. Niger Med J. 2013:54:316.

21. Sudenga SL, Rositch AF, Otieno WA, Smith JS. Knowledge, attitudes, practices, and perceived risk of cervical cancer among Kenyan women: brief report. Int J Gynecol Cancer. 2013;23:895-9.

22. Basu P, Hassan S, Fileeshia F, Mohamed S, Nahoodha A, Shiuna A, et al. Knowledge, attitude and practices of women in maldives related to the risk factors, prevention and early detection of cervical cancer. Asian Pac J Cancer Prev. 2014;15:6691-5.

23. Ranabhat S, Tiwari M, Dhungana G, Shrestha R. Association of knowledge, attitude and demographic variables with cervical pap smear practice in Nepal. Asian Pac J Cancer Prev. 2014;15:8905-10.

\section{Submit your next manuscript to BioMed Central and we will help you at every step:}

- We accept pre-submission inquiries

- Our selector tool helps you to find the most relevant journal

- We provide round the clock customer support

- Convenient online submission

- Thorough peer review

- Inclusion in PubMed and all major indexing services

- Maximum visibility for your research

Submit your manuscript at www.biomedcentral.com/submit 